\title{
Analysis of Trans Fat in Edible Oils with Cooking Process
}

\author{
Juhee Song', Joohyeok Park', Jinyeong Jung ', Chankyu Lee', Seo Yeoung Gim', \\ HyeJung Ka', BoRa Yi', Mi-Ja Kim ${ }^{2}$, Cho-il Kim ${ }^{3}$ and JaeHwan Lee ${ }^{1}$ \\ 'Department of Food Science and Biotechnology, Sungkyunkwan University, Suwon, Korea \\ ${ }^{2}$ Department of Food and Nutrition, Kangwon National University, Samcheok, Korea \\ ${ }^{3}$ Bureau of Health Industry Promotion, Korea Health Industry Development Institute, Chungcheongbuk-do, Korea
}

(Received August 12, 2015; Revised September 11, 2015; Accepted September 18, 2015)

\begin{abstract}
Trans fat is a unsaturated fatty acid with trans configuration and separated double bonds. Analytical methods have been introduced to analyze trans fat content in foods including infrared (IR) spectroscopy, gas chromatography (GC), Fourier transform-infrared (FT-IR) spectroscopy, reverses-phase silver ion high performance liquid chromatography, and silver nitrate thin layer chromatography. Currently, FT-IR spectroscopy and GC are mostly used methods. Trans fat content in 6 vegetable oils were analyzed and processing effects including baking, stir-frying, pan-frying, and frying on the formation of trans fat in corn oil was evaluated by GC. Among tested vegetable oils, corn oil has $0.25 \mathrm{~g}$ trans fat $/ 100 \mathrm{~g}$, whereas other oils including rapeseed, soybean, olive, perilla, and sesame oils did not have detectable amount of trans fat content. Among cooking methods, stir-frying increased trans fat in corn oil whereas baking, pan-frying, and frying procedures did not make changes in trans fat content compared to untreated corn oils. However, the trans fat content was so low and food label can be declared as ' 0 ' trans based on the regulation of Ministry of Food ad Drug Safety (MFDS) $(<2 \mathrm{~g} / 100 \mathrm{~g}$ edible oil).
\end{abstract}

Key words: Trans fat, Vegetable oil, Processing procedure, Fatty acid, Gas chromatography

\section{INTRODUCTION}

Trans fat is unsaturated fatty acid with trans configuration rather than cis configuration, which is a normal isomer in naturally occurring lipids. However, polyunsaturated fatty acids having double bonds with conjugated forms such as conjugated linoleic acid are not categorized as trans fat due to their health beneficial influence. Hydrogenation, which uses hydrogen gas and metal catalysts to reduce the degree of unsaturation and provide proper physical characteristics in oils since 1890 s, is a major process to generate trans fat in our daily diet. Margarine, shortening, and butters are well-known solid fat containing trans isomers. Other sources of trans fat in our daily diet are microorganisms in the rumens of ruminant animals through biohydrogenation. Roseburia hominis A2-183T, Roseburia inulinivorans

Correspondence to: JaeHwan Lee, Department of Food Science and Biotechnology, Sungkyunkwan University, 2066 Seobu-ro, Jangan-gu, Suwon, Gyeonggi-do 16419, Korea

E-mail: s3hun@skku.edu

This is an Open-Access article distributed under the terms of the Creative Commons Attribution Non-Commercial License (http:// creativecommons.org/licenses/by-nc/3.0) which permits unrestricted non-commercial use, distribution, and reproduction in any medium, provided the original work is properly cited.
A2-192T and Ruminococcus obeum-like strain A2-162 can produce trans fatty acids from ruminant sources $(1,2)$. Dairy products including meat, milk, and butter possess about $2 \sim 5 \%$ of trans fat due to the activities of microorganisms in ruminant animals such as cows and goats (3).

The profiles of trans fat from commercially available partially hydrogenated oils and natural resources are not the same. Vaccenic acid (C18:1n11t), which has trans structure in carbon 11 of octadecenoic acid, is major monounsaturated trans fat from biohydrogenation whereas partially hydrogenated oils by chemical hydrogenation have more elaidic acid (C18:1n9t), which has trans part in carbon 9 of octadecenoic acid $(1,2)$.

Detrimental health implication of trans fat diet has been filed up for more than four decades. Epidemiologic and biochemical evidence confirmed that excessive trans fats in the diet are a significant risk factor for cardiovascular disease. Health effects of trans fat could be due to the structures of trans fat $(1,2)$. The melting point of stearic acid (C18:0), oleic acid $(\mathrm{C} 18: \ln 9 c)$, and elaidic acid $(\mathrm{C} 18: \ln 9 t)$, are 70 , -5 , and $42^{\circ} \mathrm{C}$, respectively, which implies that trans fat exists as solid at room temperature and human body temperature like saturated fat.

A number of methods have been introduced to determine total trans fat content including infrared (IR) spectroscopy, 
gas chromatography (GC), Fourier transform-infrared (FTIR) spectroscopy, reverses-phase silver ion high performance liquid chromatography (HPLC), and silver nitrate thin layer chromatography ( $\mathrm{AgNO}_{3}$-TLC) (4).

IR region around $967 \mathrm{~cm}^{-1}$ can detect an isolated trans double bond due to the deformation of $\mathrm{C}-\mathrm{H}$ bonds adjacent to the trans double bond. Official methods of AOCS, AOAC, and IUPAC adapted the measurement of the absorption intensity for total trans content in triacylglycerols, methyl esters of unesterified fatty acids. However, this IR method has some limitations. Triacylglycerols can absorb the region of $970 \mathrm{~cm}^{-1}$ and mono- and di-trans conjugated double bonds absorb at about 950 and 980 , and $990 \mathrm{~cm}^{-1}$, respectively, which could interfere with isolated trans fat content. This method can be useful in oils with less than $5 \%$ conjugated fatty acids due to the interference of absorption by conjugated bonds and in oils with $5 \%$ or higher content of trans fat due to the low intensity of IR absorption (5).

The advanced techniques for trans fat analysis in fats and oils are using FT-IR spectroscopy. FT-IR has more advantages including high signal to noise ratio $(\mathrm{S} / \mathrm{N})$, high wavelength calibration accuracy (reference He-Ne laser), improved light throughput and speed of analysis (Michelson interferometer), rapid and comprehensive data collection than IR spectroscopy on determining total trans fat. FT-IR technique has better accuracy in oils with less than 5\% trans fat through adjustment of baselines for example samples with more than $10 \%$ trans fat at 944 and $988 \mathrm{~cm}^{-1}$, less than $10 \%$ trans fat at 944 and $985 \mathrm{~cm}^{-1}$, and below $5 \%$ trans fat at 944 and $973 \mathrm{~cm}^{-1}$ (6). These FT-IR methods used carbon disulfide like IR method, which may lead to stratification, vapor and air bubbles within cells. A Michelson Interferometer in FT-IR can help all the wavelength of IR pass through samples simultaneously. FT-IR can determine the content of trans fat with high correlation coefficient without using carbon disulfide. trans Peak areas can be integrated from 945 to $990 \mathrm{~cm}^{-1}$ and quantification can be done through fitting the measured trans areas with a second order polynomial (7). Official method of AOCS and AOAC using the FT-IR can be used for quantitative determination of trans fat above 1 and 5\%, respectively. Some disadvantages of FT-IR method for determining trans fat are overestimating the content of trans fat, interference from conjugated fatty acids, and the expressing results as equivalent of elaidic acid (C18:1 n9t) content (4).

The next advance in trans fat analysis by FT-IR spectroscopy came from using attenuated total reflection-Fourier transform-infrared spectroscopy (ATR-FT-IR). When light strikes two different medium at normal condition, some light partially transmitted and partially reflected. However, in internal reflection mode, light is reflected inside the crystal and evanescent wave is then propagating away from the surface of the crystal like trans fat. The intensity of this wave is partly attenuated by IR and this internal reflection is known as ATR.

ATR-FT-IR has been introduced to measure trans fat in oils and fat samples using middle IR range and the ATR cell. This technique requires prior extraction of fat from food samples while further derivatization and use of harmful solvents were not necessary (8). Priego-Capote et al. (9) used ATR-IR spectroscopy for determination of total fat and trans fatty-acids content in bakery products. Da Costa Filho (3) develop a method determining trans fatty acids in edible oils using ATR-FT-IR over a wavelength range of 600$4000 \mathrm{~cm}^{-1}$ and the peak height at $966.3 \mathrm{~cm}^{-1}$ was electronically converted to its negative second derivative for trans fat content. This ATR-FT-IR can determine less than 1\% trans fat in edible oils and fats including palm, peanut, soybean, and sunflower oils.

GC for the analysis of fatty acid methyl esters (FAME) are the most convenient and accurate method. Therefore, GC methods can isolate trans configuration from cis forms, which can not be achieved by IR or FT-IR spectroscopy methods (10). Conventional GC for analysis of FAME use a slightly polar column using polyglycol Carbowax-20 because natural oils have majorly cis form of double bonds. Separation of trans/cis configuration requires more polar stationary phase including SP-2560, SP-2340, OV-275, BPX-70 or CP-SIL-88 using highly polar cyanosilicone. Recently, the length of capillary columns extended to 100 or $120 \mathrm{~m}$ to make better resolution if the isolation of cis/trans isomers (4). American Oil Chemists Society (AOCS) (11) approved official method Ce 1h-05 for the determination of cis, transsaturated, monounsaturated, and polyunsaturated fatty acids in vegetable or non-ruminant animal oils and fats by capillary GC with a flame ionization detector (FID). Also, Official Method of Analysis 996.06 revised by the AOAC International (AOAC) adapted 100-m high-polarity capillary column as a stationary phase for GC-FID method (10).

Different detectors like mass spectrometry (MS) coupled with GC were introduced for trans fat analysis (12). However, overlaps and co-elution of cis/trans isomers observed in chromatograms from GC-FID.

In case of foods from ruminant animals like dairy products, different extraction or GC conditions are needed due to a large number of short chained fatty acids and the variety of different molecular structures (13).

A combination of GC and IR methods was suggested by Ratnayake et al. (14). Total trans fat measured by IR can be corrected using a formula: IR trans $=\% 18: t+0.84 \mathrm{x}$ $\% 18: 2 t t+1.74 \times \% 18: 3 t$, which can be obtained from GC analysis for trans FAME. The combination of GC and IR methods are useful to determine trans fat content in partially hydrogenated vegetable oil containing more than $5 \%$ trans fat. Cruz-Hernandez et al. (15) analyzed conjugated linoleic acids and trans-18:1 isomers in dairy fats by using a combination of GC, silver-ion TLC/GC, and silver-ion liquid chromatography. 
Reversed-phase HPLC can separate fatty acids based on the apparent carbon number, which is the number of carbons - $2 \mathrm{x}$ number of double bonds. This technique cannot separate cis/trans isomers in monounsaturated fatty acids whereas can separate linoleic acid isomers from non-octadecadienoic acids or conjugated linoleic acid. Silver salts can form more stable complex with cis isomers and $\mathrm{AgNO}_{3}$ rather than trans isomer. This properties can be used to differentiate cis/trans isomers and applied to TLC, HPLC, and solid phase extraction columns (4).

Analysis of fatty acid profiles in one of typical procedures in food industry because providing information on the content of trans fat should be included in food label. Accurate information on the content of trans fat in foods can come from proper techniques for extracting lipids, saponification, and methylation of fatty acids. Each of above steps may include error sources for the manual operation, parameter settings, and/or data interpretations by the analysts (10).

Several official methods have been approved by any official national or international entity. As more accurate and precise methods and technologies are developed, some official methods are not frequently used whereas some are still valid. In Korea, officially approved analysis methods have been suggested in Korea Food Code. All the government agencies and laboratories from food industry should use this official method to certify the content of trans fat in the products.

Many reports have conducted on the fatty acid profiles and trans fat content in edible oils. However, effects of conventional cooking procedures including baking, stir-frying, pan-frying, and frying on the formation of trans fat in edible oils are scarce in the literature. Especially, vegetable oils from real cooking conditions for Total Dietary Study (TDS) in Korea have not been tried.

The objective of this study was to analyze trans fat content in commonly consumed vegetable oils and to find out effects of conventional cooking treatment on the formation of trans fat.

\section{MATERIALS AND METHODS}

Materials. Triundecanoin, elaidic acid, mixtures of standard fatty acids, and $\mathrm{BF}_{3}$ were purchased from SigmaAldrich (St. Louis, MO, USA). Other chemicals were purchased from Daejung Chemical Co. (Seoul, Korea). Vegetable oils including corn, rapeseed, soybean, olive, perilla, and sesame oils were obtained from 18 large glossary markets located in 9 different cities in Korea for the purpose of Korean TDS from the year of 2013 to the year of 2016. The selected 9 cities were Seoul, Busan, Incheon, Daegu, Daejeon, Gwangju, Ulsan, Changwon, and Suwon, which had more than 1 million population. Best-selling branded vegetable oils, which were purchased from 18 different sampling sites, were sampled equal amount and blended to make a pool of oil. Each oil sample was provided in triplicate with separated bottles.

Sample preparation. Vegetable oils and corn oils with cooking procedures were kindly treated by Korea Health Industry Development Institute (KHIDI) based on the procedures of Korea Health and Nutrition Examination Survey conducted from the year of 2008 to the year of 2011. Cooking processes were selected as baking, stir-frying, pan-frying, and frying by KHIDI. Briefly, baking procedure was done using a preheated pan (diameter of $25 \mathrm{~cm}$ ) at $180^{\circ} \mathrm{C}$. Corn oil was spread in a preheated pan with a thin layer and maintained at $180^{\circ} \mathrm{C}$ for $1 \sim 2 \mathrm{~min}$. Stir-frying procedure for corn oil was done in the preheated pan at $170^{\circ} \mathrm{C}$. Corn oil in the pan was stirred continuously by a spatula for $2 \mathrm{~min}$. For pan-frying procedure, corn oil was poured in the preheated pan at $170^{\circ} \mathrm{C}$ and was stirred 2 or 3 times per min by the spatula for $2 \mathrm{~min}$. Frying was done using a shallow pan (diameter of $30 \mathrm{~cm}$ and height of $20 \mathrm{~cm}$ ). Corn oil was filled in the shallow pan at the height of $10 \mathrm{~cm}$ and heated at $180^{\circ} \mathrm{C}$. The corn oil in the shallow pan was further heated for 2 more min at $180^{\circ} \mathrm{C}$. Corn oils sample with different cooking procedure were prepared in separated 3 bottles.

Fatty acid analysis by gas chromatography with a flame ionization detector (FID). Triundecanoin (C11:0), an internal standard, was dissolved in $n$-hexane and added to the extracted oil to the concentration of 1,000 ppm (w/v) and solvent was removed under nitrogen gas flow. Fatty acids were derivatized to fatty acid methyl esters (FAME) using $\mathrm{BF}_{3} / \mathrm{MeOH}$ (14\% boron trifluoride) and analyzed by GC according to AOAC 969.33 (16) with some modification. FAME was analyzed by Hewlett-Packard 6890 gas chromatograph (Agilent Technologies) with a FID, and a SP-2560 column $(100 \mathrm{~m} \times 0.25 \mathrm{~mm}$ ID, $0.20 \mu \mathrm{m}$ film $)$ from Supelco (Bellefonte, PA, USA). The oven temperature started at $100^{\circ} \mathrm{C}$ for $4 \mathrm{~min}$, increased to $225^{\circ} \mathrm{C}$ at $3^{\circ} \mathrm{C} / \mathrm{min}$, and held at $225^{\circ} \mathrm{C}$ for $20 \mathrm{~min}$. The temperatures of injector and detector were 225 and $285^{\circ} \mathrm{C}$, respectively. The flow rate of helium carrier gas was $0.75 \mathrm{~mL} / \mathrm{min}$, the injection volume was $1 \mu \mathrm{L}$, and the split ratio was 1:200. Peaks of GC chromatograms were identified comparing the retention times of a mixture of standard fatty acid methyl esters (SigmaAldrich). Each peak of fatty acid was quantified using an equivalent of the concentration of the internal standard. Samples were separately analyzed in triplicate.

\section{RESULTS AND DISCUSSION}

Chromatograms of fatty acid standard mixture (a) and corn oil (b) are shown in Fig. 1. The retention times for internal standard (C11:0), elaidic acid (C18:1n9t), and trans linoleic acid (C18:2n6t) were 25.71, 43.68, and $45.12 \mathrm{~min}$, respectively. Mixtures of standard fatty acids were well sep- 

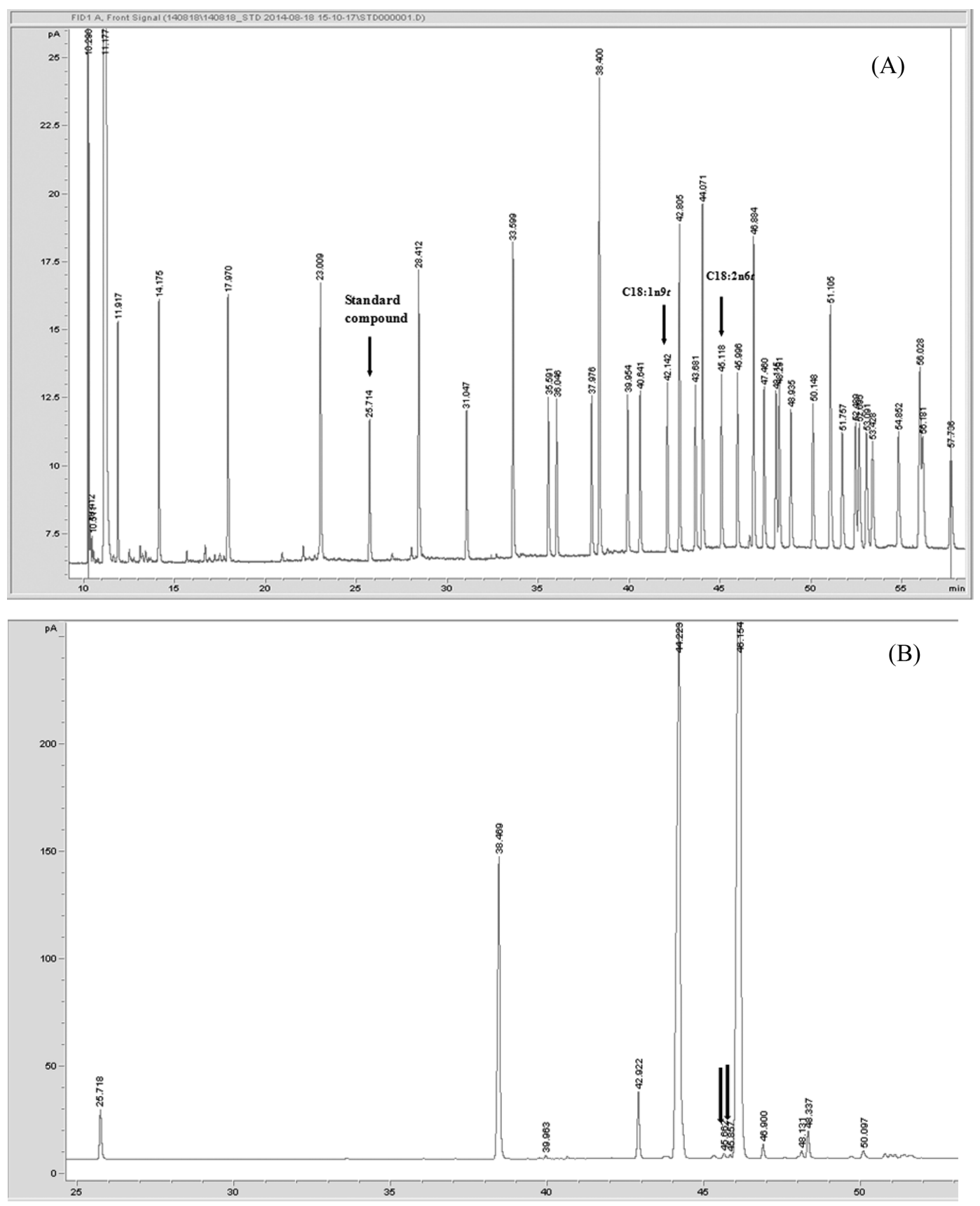

Time (min)

Fig. 1. Chromatograms of fatty acid standard mixture (A) and of corn oil (B). Arrows indicate the peaks of trans fatty acids.

arated using current analysis method.

Fatty acid profiles of 5 edible oils are shown in Table 1. Fatty acid profiles in vegetable oils were different substantially. Corn oil had high linoleic acid $(50.28 \mathrm{~g} / 100 \mathrm{~g})$, followed by oleic acid (31.32 g/100 g), palmitic acid (12.65 g/ $100 \mathrm{~g})$, and stearic acid $(2.24 \mathrm{~g} / 100 \mathrm{~g})$. Rapeseed oils had oleic acid (68.20 g/100 g), followed by linoleic acid (15.38 g/ $100 \mathrm{~g})$, linolenic acid (7.70 g/100 g) and palmitic acid (5.69 g/
$100 \mathrm{~g})$. Soybean oil had high linoleic acid (45.23 g/100 g), followed by oleic acid (27.03 g/100 g), palmitic acid (16.05 g/ $100 \mathrm{~g})$, and linolenic acid $(6.09 \mathrm{~g} / 100 \mathrm{~g})$. Olive oil had the high oleic acid $(78.11 \mathrm{~g} / 100 \mathrm{~g})$ as expected whereas perilla oil had high linolenic acid (57.78 g/100 g).

Corn oil had $0.25 \mathrm{~g} \mathrm{C} 18: 2 \mathrm{n} 6 \mathrm{t} / 100 \mathrm{~g}$ whereas other oils including rapeseed, soybean, olive, perilla, and sesame oils did not possess trans fat. Presence of trans fat in corn oil 
Table 1. Major fatty acid profiles and trans fat content in vegetable oils $(\mathrm{g} / 100 \mathrm{~g})$

\begin{tabular}{|c|c|c|c|c|c|c|c|c|c|c|c|c|}
\hline \multirow{2}{*}{ Sample } & \multicolumn{10}{|c|}{ Fatty acid } & \multicolumn{2}{|c|}{ Trans fatty acid } \\
\hline & $16: 0$ & $16: 1$ & $18: 0$ & $18: 1$ & $18: 2$ & $18: 3$ & $20: 0$ & $20: 1$ & $20: 2$ & $22: 0$ & $\mathrm{C} 18: \ln 9 t$ & $\mathrm{C} 18: 2 \mathrm{n} 6 t$ \\
\hline Corn oil & $\begin{array}{c}12.65 \pm \\
0.15^{1)}\end{array}$ & $\begin{array}{c}0.11 \pm \\
0.00\end{array}$ & $\begin{array}{c}2.24 \pm \\
0.02\end{array}$ & $\begin{array}{c}31.32 \pm \\
0.34\end{array}$ & $\begin{array}{c}50.28 \pm \\
0.61\end{array}$ & $\begin{array}{c}0.93 \pm \\
0.02\end{array}$ & $\begin{array}{c}0.52 \pm \\
0.00\end{array}$ & $\begin{array}{c}0.23 \pm \\
0.00\end{array}$ & $\begin{array}{c}0.18 \pm \\
0.14\end{array}$ & N.D. ${ }^{2)}$ & N.D. & $\begin{array}{c}0.25 \pm \\
0.01\end{array}$ \\
\hline Rapeseed oil & $\begin{array}{c}5.69 \pm \\
0.13\end{array}$ & N.D. & $\begin{array}{c}2.28 \pm \\
0.01\end{array}$ & $\begin{array}{c}68.20 \pm \\
0.24\end{array}$ & $\begin{array}{c}15.38 \pm \\
0.12\end{array}$ & $\begin{array}{c}7.70 \pm \\
0.08\end{array}$ & N.D. & $\begin{array}{c}0.75 \pm \\
0.08\end{array}$ & N.D. & N.D. & N.D. & N.D. \\
\hline Soybean oil & $\begin{array}{c}16.05 \pm \\
0.02\end{array}$ & N.D. & $\begin{array}{c}5.59 \pm \\
0.04\end{array}$ & $\begin{array}{c}27.03 \pm \\
0.01\end{array}$ & $\begin{array}{c}45.23 \pm \\
0.08\end{array}$ & $\begin{array}{c}6.09 \pm \\
0.02\end{array}$ & N.D. & N.D. & N.D. & N.D. & N.D. & N.D. \\
\hline Olive oil & $\begin{array}{c}13.65 \pm \\
0.01\end{array}$ & $\begin{array}{c}0.75 \pm \\
0.00\end{array}$ & $\begin{array}{c}3.38 \pm \\
0.02\end{array}$ & $\begin{array}{c}78.11 \pm \\
0.05\end{array}$ & $\begin{array}{c}3.61 \pm \\
0.02\end{array}$ & $\begin{array}{c}0.49 \pm \\
0.02\end{array}$ & N.D. & N.D. & N.D. & N.D. & N.D. & N.D. \\
\hline Perilla seed oil & $\begin{array}{c}6.87 \pm \\
0.08\end{array}$ & $\begin{array}{c}0.22 \pm \\
0.00\end{array}$ & $\begin{array}{c}2.13 \pm \\
0.02\end{array}$ & $\begin{array}{c}19.71 \pm \\
0.15\end{array}$ & $\begin{array}{c}10.71 \pm \\
0.14\end{array}$ & $\begin{array}{c}57.78 \pm \\
0.27\end{array}$ & $\begin{array}{c}0.16 \pm \\
0.00\end{array}$ & $\begin{array}{c}0.12 \pm \\
0.00\end{array}$ & N.D. & N.D. & N.D. & N.D. \\
\hline Sesame oil & $\begin{array}{c}10.58 \pm \\
0.60\end{array}$ & N.D. & $\begin{array}{c}6.18 \pm \\
0.39\end{array}$ & $\begin{array}{c}41.41 \pm \\
2.94\end{array}$ & $\begin{array}{c}33.83 \pm \\
1.73\end{array}$ & N.D. & $\begin{array}{c}0.64 \pm \\
0.03\end{array}$ & N.D. & N.D. & $\begin{array}{c}0.08 \pm \\
0.14\end{array}$ & N.D. & N.D. \\
\hline
\end{tabular}

${ }^{1)}$ Mean \pm standard deviation $(\mathrm{n}=3)$.

${ }^{2)}$ Not detected.

can be found in other previous reports. Zhang et al. (17) analyzed C18 trans fatty acids in edible oils including corn, sunflower, and olive oils using GC-mass spectrometry and found out that $1.29 \mathrm{~g}$ trans fat $/ 100 \mathrm{~g}$ FAME in corn oil. C18:2 and C18:3 trans fat were almost equally responsible for the trans fat in corn oil (17). Trans fat in 19 corn oil in China was all detected ranging from 0.56 to $4.75 \mathrm{~g} / 100 \mathrm{~g}$ with average of $2.01 \mathrm{~g} / 100 \mathrm{~g}$ (18). Mossoba et al. (19) analyzed fatty acid profiles in edible oils including canola, coconut, corn, flax, grapeseed, olive, peanut, safflower, shortening, sunflower, and walnut oils using FT-NIR and GC methods and found out 0.36 to $0.99 \%$ trans fat in corn oil by GC method and 1.2 to $1.4 \%$ trans fat in corn oil by FT-NIR method. A value of $0 \mathrm{~g}$ trans fat per serving can be labeled if trans fat content is below $0.5 \mathrm{~g}$ per serving in US. Average serving size of oils in US is $14 \mathrm{~g}$, which corresponds to a trans fat content of $<3.6 \%$ in the US. The detected $0.25 \%$ trans fat in corn oil is less than limitation and can be declared as 0 trans fat in food label.

Effects of cooking methods on the changes of trans fat content in corn oils are shown in Table 2. Processing including baking, stir-frying, pan-frying, and frying used thermal

Table 2. Effects of cooking process on trans fat content in corn oil $(\mathrm{g} / 100 \mathrm{~g})$

\begin{tabular}{lcc}
\hline \hline \multirow{2}{*}{ Processing method } & \multicolumn{2}{c}{ Trans fatty acid } \\
\cline { 2 - 3 } & C18:1n9t & C18:2n6t \\
\hline Raw & N.D. ${ }^{1)}$ & $0.25 \pm 0.01^{2)}$ \\
Baking & N.D. & $0.26 \pm 0.01$ \\
Stir-frying & $0.48 \pm 0.32$ & $0.56 \pm 0.16$ \\
Pan-frying & N.D. & $0.27 \pm 0.01$ \\
Frying & N.D. & $0.26 \pm 0.01$ \\
\hline
\end{tabular}

\footnotetext{
${ }^{1)}$ Not detected.

${ }^{2)}$ Mean \pm standard deviation $(n=3)$.
}

energy and lipid oxidation occurred in corn oils. Among cooking methods, stir-frying produced higher trans fat in corn oil than new corn oils whereas baking, pan-frying, and frying procedures did not make changes among trans fat content in corn oils. High temperature treatment can cause the formation of trans fat in oils through oxidation process. Żyżelewicz et al. (20) reported the formation of elaidic trans fat $(\mathrm{C} 18: 1 \mathrm{n} 9 t)$ in cocoa buffer extracted from roasted beans when roasting temperature was $135^{\circ} \mathrm{C}$ and roasting duration was $15 \mathrm{~min}$. Tsuzuki et al. (21) confirmed the significant increases in trans fatty acids in edible oils during frying and heating process. When sliced raw potatoes were fried at $180^{\circ} \mathrm{C}$, frying oils from potato frying had higher trans fatty acid than oils with the same temperature heating without potato frying (21).

Trans formation from cis configuration in unsaturated lipids is inevitable steps during autoxidation, which is one of basic lipid oxidation mechanisms. Autoxidation is known as a free radical chain reaction with initiation, propagation, and final steps. Initial step is a formation of lipid radicals $(\mathrm{L} \cdot)$ by losing hydrogen atom from unsaturated lipid (LH). Double bonds in cis configuration are unstable and tend to form trans configuration, which is more stable form than cis form (22). The higher temperature accelerates the reaction rates of oxidation and the more trans fat is generated.

Among tested cooking methods, stir-frying procedure at $170^{\circ} \mathrm{C}$ heating and continuous stirring process may accelerate the rates of lipid oxidation and formation of trans fat compared to other cooking procedures. However, the content of trans fat in vegetable oil after stir-frying process was far below the trans fat level compared to other food products like margarine made of partially hydrogenated oils (23). The content of trans fat in edible oils was so low and food label can be declared as ' 0 ' trans fat based on the regulation of Ministry of Food ad Drug Safety (MFDS). In 
case of edible oils, trans fat content below $2 \mathrm{~g}$ per $100 \mathrm{~g}$ oil can be declared as ' 0 ' trans.

In conclusion, GC-FID is a reliable and accurate technique for the analysis of trans fat in vegetable oils. Among conventional cooking methods, stir-frying step can increase trans fat content in edible oils due to the high temperature treatment and continuous stirring, which might accelerate the rates of lipid oxidation. This GC-FID technique can be applied to any food matrix with proper lipid extraction methods for the quantification of trans fat content.

\section{ACKNOWLEDGMENTS}

This research was supported by a grant (13162MFDS049) from Ministry of Food and Drug Safety in 2013-2015.

\section{REFERENCES}

1. Ganguly, R. and Pierce, G.N. (2015) The toxicity of dietary trans fat. Food Chem. Toxicol., 78, 170-176.

2. Remig, V., Franklin, B., Margolis, S., Kostas, G., Nece, T. and Street, J.C. (2010) Trans tats in America: a review of their use, consumption, health implications, and regulation. J. Am. Diet. Assoc., 110, 585-592.

3. da Costa Filho, P.A. (2014) Developing a rapid and sensitive method for determination of trans-fatty acids in edible oils using middle-infrared spectroscopy. Food Chem., 158, 1-7.

4. Juanéda, P. Ledoux, M. and Sébédio, J.L. (2007) Analytical methods for determination of trans fatty acid content in food. Eur. J. Lipid Sci. Technol., 109, 901-917.

5. Madison, B.L., Depalma, R.A. and D'Alonzo, R.P. (1982) Accurate determination of trans isomers in shortenings and edible oils by infrared spectrophotometry. J. Am. Oil Chem. Soc., 59,178-181.

6. Lanser, A.C. and Emken, E.A. (1988) Comparison of FTIR and capillary gas chromatograpic methods for quantitation of trans unsaturation of fatty acid methyl esters. J. Am. Oil Chem. Soc., 65, 1483-1487.

7. Sletter, R.T. and Matlock, M.G. (1988) Automated quantitative analysis of isolated (nonconjugated) trans isomers using Fourier transform infrared spectroscopy incorporating improvements in the procedure. J. Am. Oil Chem. Soc., 66,121-127.

8. Mossoba, M.M., Seiler, A., Steinhart, H., Kramer, J.K.G., Rodrigues-Saona, L., Griffith, A.P., Pierceall, R., van de Voort, F.R., Sedman, J., Ismail, A.A., Barr, D., Da Costa Filho, P.A., Li, H., Zhang, Y., Liu, X. and Bradley, M. (2010) Regulatory infrared spectroscopic method for the rapid determination of total isolated trans fat: a collaborative study. $J$. Am. Oil Chem. Soc., 88, 39-46.

9. Priego-Capote, F., Ruiz-Jiménez, J., García-Olmo, J. and Luque de Castro, M.D. (2004) Fast method for the determination of total fat and trans fatty-acids content in bakery products based on microwave-assisted Soxhlet extraction and medium infrared spectroscopy detection. Anal. Chim. Acta,
517, 13-20.

10. Delmonte, P. and Rader, J.I. (2007) Evaluation of gas chromatographic methods for the determination of trans fat. Anal. Bioanal. Chem., 389, 77-85.

11. American Oil Chemists Society. (2009) Official method Ce 1h-05. AOCS, Champaign, IL.

12. Huang, Z., Wang, B. and Crenshaw, A.A. (2006) A simple method for the analysis of trans fatty acid with GC-MS and $\mathrm{AT}^{\mathrm{TM}}$-Silar-90 capillary column. Food Chem., 90, 593-598.

13. Schröeder, M. and Vetter, W. (2013) Detection of 430 fatty acid methyl esters from a transesterified butter sample. J. Am. Oil Chem. Soc., 90, 771-790.

14. Ratnayake, W.M.N., Hollywood, R., O'Grady, E. and BeareRogers, J.L. (1990) Determination of cis and trans-octadecenoic acids in margarines by gas liquid chromatography-infrared spectrophotometry. J. Am. Oil Chem. Soc., 67, 804-810.

15. Cruz-Hernandez, C., Deng, Z., Zhou, J., Hill, A.R., Yurawecz, M.P., Delmonte, P., Mossoba, M.M., Dugan, M.E. and Kramer, J.K. (2004) Methods for analysis of conjugated linoleic acids and trans-18:1 isomers in dairy fats by using a combination of gas chromatography, silver-ion thin-layer chromatography/gas chromatography, and silver-ion liquid chromatography. J. AOAC Int., 87, 545-562.

16. AOAC International. (2000) Official methods of analysis of AOAC international. Fatty acids in oils and fats [969.33], Rockville.

17. Zhang, M., Yang, X., Zhao, H.T., Dong, A.J., Wang, J., Liu, G.Y., Wang, P., Cheng, C.L. and Zhang, H. (2015) A quick method for routine analysis of $\mathrm{C} 18$ trans fatty acids in nonhydrogenated edible vegetable oils by gas chromatographymass spectrometry. Food Control, 57, 293-301.

18. Hou, J.C., Wang, F., Wang, Y.T., Xu, J. and Zhang, C.W. (2012) Assessment of trans fatty acids in edible oils in China. Food Control, 25, 211-215.

19. Mossoba, M.M., Azizian, H., Tyburczy, C., Kramer, J.K.G., Delmonte, P., Fardin Kia, A.R. and Rader, J.I. (2013) Rapid FT-NIR analysis of edible oils for total SFA, MUFA, PUFA, and Trans FA with comparison to GC. J. Am. Oil Chem. Soc., 90, 757-770.

20. Żyżelewicz, D., Budryn, G., Krysiak, W., Oraca, J., Nebesny, E. and Bojczuk, M. (2014) Influence of roasting conditions on fatty acid composition and oxidative changes of cocoa butter extracted from cocoa bean of Forastero variety cultivated in Togo. Food Res. Int., 63, 328-343.

21. Tsuzuki, W., Matsuoka, A. and Ushida, K. (2010) Formation of trans fatty acids in edible oils during the frying and heating process. Food Chem., 123, 976-982.

22. Choe, E. and Min, D.B. (2006) Mechanisms and factors for edible oil oxidation. Compr. Rev. Food Sci. Food Saf., 5, 169186.

23. Ratnayake, W.M.N., Gagnon, C., Dumais, L., Lillycrop, W., Wong, L., Meleta, M. and Calway, P. (2007) trans Fatty acid content of Canadian margarines prior to mandatory trans fat labelling. J. Am. Oil Chem. Soc., 84, 817-825. 